\title{
Making the right software choice for clinically used equipment in radiation oncology
}

\author{
Hilke Vorwerk ${ }^{*}$, Klemens Zink², Daniela Michaela Wagner ${ }^{3}$ and Rita Engenhart-Cabillic ${ }^{1}$
}

\begin{abstract}
The customer of a new system for clinical use in radiation oncology must consider many options in order to find the optimal combination of software tools. Many commercial systems are available and each system has a large number of technical features. However an appraisal of the technical capabilities, especially the options for clinical implementations, is hardly assessable at first view.

The intention of this article was to generate an assessment of the necessary functionalities for high precision radiotherapy and their integration in ROKIS (Radiation oncology clinic information system) for future customers, especially with regard to clinical applicability. Therefore we analysed the clinically required software functionalities and divided them into three categories: minimal, enhanced and optimal requirements for high conformal radiation treatment.
\end{abstract}

Keywords: Treatment planning system, ROKIS, High precision radiotherapy, Software choice, Technical applicability, Radiation therapy

\section{Introduction}

Technical functionality of all soft- and hardware components is a prerequisite for the application of high conformal radiation treatment. Most considerations include technical functionalities but not the clinical practicability. Hence the available tools are mostly limited in their applicability and sometimes, because of the absence of implementation, not applicable at all. The most important consideration is whether it is possible to implement the technical functionalities or not. Therefore we summarized the available technical functionalities and analysed them according to their clinical practicability. We focused on the functionality of the treatment planning system, the patient verification at the accelerator and the ROKIS system because these factors predominantly contribute to the clinical applicability of high precision radiotherapy. This study should assist the reader in making the right software and hardware choice for the implementation of highly conformal radiotherapy in the daily clinical practice.

\footnotetext{
*Correspondence: vorwerk@med.uni-marburg.de

${ }^{1}$ Radiotherapy and Radiation Oncology, University Hospital Marburg,

Baldingerstrasse, Marburg 35043, Germany

Full list of author information is available at the end of the article
}

\section{Methods and materials}

Basic functionality is a prerequisite for the application of highly conformal radiation treatment. Additional tools provide increased requirements, for example safer or faster treatment [1]. In order to identify the features requested, we generated a list based on all features available from a larger radiation oncology vendors. Then, we classified all functionalities into three groups:

(1)minimal requirements for high conformal radiation treatment

(2)enhanced requirements for high conformal radiation treatment (for example faster and/or safer treatment)

(3)optimal requirements for high conformal radiation treatment (best possible features)

The tools, which establish the basic requirements for high conformal radiotherapy for nearly all patients of a clinical department have been analyzed in this article. In our considerations, we included high precision therapy for different clinical cases such as head or neck region as well as high dosage treatment of the prostate. We did not include considerations for special areas such as cranial or extra-cranial radiosurgery or brachytherapy. 


\section{Results}

The analysis of the features in the above mentioned groups are summarised in Table 1, Table 2, Table 3, Table 4, and Table 5. For clarity the data were divided into three classifications safety, accuracy and efficiency (Table 1, Table 2 and Table 3). Thereby, the data import, registration and structure contouring influence all three categories. The dicom coordinates from the CT must either be transformed before being imported into the planning system or a new origin must be defined in the treatment planning system, which can result in errors. Therefore the optimal solution is the automatic transformation, either before or directly after the import into the treatment planning system. The CT software and the infrastructure often limit this possibility and the treatment planning systems are repeatedly not able to compensate for this problem. Most of the different contouring tools are basic tools; correction tools and 3D options are enhanced and optimal requirements. Most notably, transferring and copying structures between different data sets is very important for high precision radiotherapy. The demand on the planning system is extensive concerning accuracy as well as safety aspects. (Table 1, Table 2 and Table 3). Special focus should be set on the basic minimal requirement, which is the ability to create a sum of different data sets. Most ROKIS systems offer the requested tools, but the integration of the various existing tools into one system is still under development. Patient verification is the system with the highest demand on new tools in the future, especially for the clinical implementation of single features. Accuracy and safety are most important for the clinical applicability of this feature.

For adaptive treatment most of the tools only have to met the minimal requirements gin in Table 4. These tools are available but still much too slow to be implemented in daily clinical routine. Respiratory gating is gaining in importance in the future (Table 5), if we can minimize or correlate the differences between interior and exterior patient movement. The systems available today from the radiation oncology vendors already meet most requirements.

\section{Discussion}

The ability to assess the clinical applicability and compatibility of software tools is the most important requisite for smooth and fast processes in clinical work and is often underestimated. The technical features are described in detail by the vendor and an optimal clinical implementation is presupposed, but in many cases the integration into the clinical workflow is non-optimal. For the customer it is very difficult and time consuming to analyse all the tools in detail. Therefore we summarized the technical features required for a smooth clinical process, in order to help the customer to make the right software choice.

Automatic rigid registration of two different data sets based on grey scale values or with dicom coordinates should be implemented in the treatment planning systems. Of great importance is the ability of the software systems to registrate more than two data sets. One example is, for instance, the ability to register the planning CT of a patient with a head tumour to the T1-weighted MRI and in addition to the FLAIR (fluid attenuated inversion recovery) MRI. All treatment systems should be capable of dealing with combined PET-CT data, which not only compromise a high precision therapy treatment but also conventional treatments such as radiotherapy for patients with lung cancer. If the registration is not lockable this can result in serious treatment failures (Table 1). Meanwhile flexible registration, which is important for the accuracy (Table 2), is available, but often as an extra tool with higher costs. The automatic registration errors are not documented well by the manufacturers. At the time, only few evaluations were made concerning the technical uncertainties [2]. On that account we recommend an accuracy of the technical rigid registration uncertainties determined by phantom measurements of no more than $0.2 \mathrm{~mm}$ for an optimal treatment. Flexible registration in both directions (from CBCT to planning CT or vice versa) should ideally be implemented in the planning system in the future [3]. The significance seems to be high, but is not evaluated satisfactorily [2]. Generally the registration results and the registration time of the different systems should be analysed carefully.

A basic feature for the accuracy is the ability to copy a structure from one data set to another rigid registered data set (Table 2). This should be evaluated before purchasing a new system. Also the representation of one structure in another registered data set should be investigated carefully. Some software systems are able to create all necessary structures after selecting a tumor entity associated treatment scheme, which leads to a faster contouring process (Table 3). This is important for the efficiency of the system due to the automatic segmentation of the organs at risk [4]. This tool is available for most planning systems, but is very expensive due to the expanded research requirements. Optional contouring tools only accelerate the contouring process but do not lead to a better security [5]. The safety can be increased if the user can lock the structures manually (Table 1). Additionally the structures should be automatically locked digitally after connecting to a digitally locked treatment plan. It should be checked carefully, whether these tools are implemented in the system to ensure maximum safety.

The available planning features in modern treatment planning systems are mainly acceptable [6]. The attention 
Table 1 Requirements for safety

\begin{tabular}{|c|c|c|}
\hline \multicolumn{3}{|c|}{ Data import, data registration and structure contouring } \\
\hline Minimal & Enhanced & Optimal \\
\hline Import of all CT data with dicom coordinates & $\begin{array}{l}\text { Import of all CT data with transposition of the } \\
\text { dicom coordinates (lower error source) }\end{array}$ & $\begin{array}{l}\text { Structures can be digitally locked by selected } \\
\text { users }\end{array}$ \\
\hline \multirow{4}{*}{$\begin{array}{l}\text { Import and export of treatment plans in dicom } \\
\text { format }\end{array}$} & Registration based on dicom coordinates & \\
\hline & Registration is digital lockable & \\
\hline & $\begin{array}{l}\text { Structures, which are connected to a treatment } \\
\text { plan, can't be changed (only copies or new } \\
\text { structures can be created) }\end{array}$ & \\
\hline & \multicolumn{2}{|l|}{ Requirements for treatment planning } \\
\hline Minimal & Enhanced & Optimal \\
\hline $\begin{array}{l}\text { Collapse cone or equivalent algorithm for the } \\
\text { dose calculation of photons }\end{array}$ & $\begin{array}{l}\text { Monte Carlo or equivalent algorithm for the } \\
\text { dose calculation of photons }\end{array}$ & $\begin{array}{l}\text { IMRT optimization with Monte Carlo or } \\
\text { equivalent algorithm }\end{array}$ \\
\hline Monte Carlo based radiation head model & $\begin{array}{l}\text { IMRT optimization with a Collapse cone or } \\
\text { equivalent algorithm }\end{array}$ & $\begin{array}{l}\text { Conventional IMRT optimization comprises } \\
\text { collimator and gantry rotation }\end{array}$ \\
\hline $\begin{array}{l}\text { Create sum plans of treatment plans calculated } \\
\text { on rigid registered data sets }\end{array}$ & $\begin{array}{l}\text { IMRT optimization with a direct aperture } \\
\text { calculation }\end{array}$ & $\begin{array}{l}\text { Volumetric IMRT optimization comprises } \\
\text { collimator rotation and segment selection }\end{array}$ \\
\hline $\begin{array}{l}\text { Comparison of different treatment plans } \\
\text { (calculated on any data sets) with simultaneous } \\
\text { display of the isodose distributions, DVH and BEV }\end{array}$ & $\begin{array}{l}\text { Monte Carlo or equivalent algorithm for the } \\
\text { dose calculation of electrons }\end{array}$ & $\begin{array}{l}\text { Creating of optimal DRR (DRR templates } \\
\text { producible and manual adjustable) }\end{array}$ \\
\hline $\begin{array}{l}\text { Creation of check sum every working day } \\
\text { (control of beam data) }\end{array}$ & $\begin{array}{l}\text { More than one reference dose and point can } \\
\text { be applied to a treatment plan (e.g. integrated } \\
\text { boost) }\end{array}$ & \\
\hline
\end{tabular}

\section{Requirements for ROKIS}

\section{Minimal}

Import and export of all data in general readable dicom format (structures, treatment plans, CT/MRI/ $\mathrm{PET} /$... data sets, isodoses, verification images such as planar view images or CBCT data)

Automatic link of the treatment plan to the corresponding patient

Enhanced

Treatment plans can be digitally locked by selected users

\section{Optimal}

Automatic connection between patient, prescription treatment plan and verification images

Unlocked treatment plans can't be applied to a patient

Automatic link of the treatment plan to the corresponding target volume or clinical protocol respectively

After radiation the treatment plan can't be changed or deleted (only copies can be made)

Positioning information is linked to the treatment plan

Positioning information and patient photo can be displayed in the treatment room

Remote control

Periodical upgrades available, (with no data loss, for example user defined templates)

High data integrity

\begin{tabular}{|c|c|c|}
\hline \multicolumn{3}{|c|}{ Requirements for patient verification } \\
\hline Minimal & Enhanced & Optimal \\
\hline $\begin{array}{l}\text { Automatic calculation of the } 3 \mathrm{D} \text { correction vector } \\
\text { of the treatment table ( } 2 \mathrm{D} \text { planar images and } \mathrm{CBCT} \text { ) }\end{array}$ & $\begin{array}{l}\text { Automatic link of the verification images to the } \\
\text { corresponding field of the treatment plan }\end{array}$ & $\begin{array}{l}\text { Manual adjustment of the field edges of the } \\
\text { verification field always possible }\end{array}$ \\
\hline \multicolumn{3}{|l|}{ Automatic correction of the table by the system } \\
\hline \multicolumn{3}{|l|}{$\begin{array}{l}\text { Automatic link of the verification images to the } \\
\text { corresponding treatment plan and patient }\end{array}$} \\
\hline $\begin{array}{l}\text { Correction data from offline analysis is automatically } \\
\text { sent to the treatment system }\end{array}$ & & \\
\hline
\end{tabular}


Table 2 Requirements for accuracy

\begin{tabular}{|c|c|c|}
\hline \multicolumn{3}{|c|}{ Data import, data registration and structure contouring } \\
\hline Minimal & Enhanced & Optimal \\
\hline Import of external CT, MRI or PET data & Registration of any number of data sets & Flexible registration between $\mathrm{CT}$ and $\mathrm{CT}$ \\
\hline $\begin{array}{l}\text { Automatic rigid registration of } 2 \text { different data } \\
\text { sets (e.g. CT and MRI) based on grey scale values }\end{array}$ & $\begin{array}{l}\text { Automatic registration error measured in a } \\
\text { phantom } \leq 0.5 \mathrm{~mm}\end{array}$ & $\begin{array}{l}\text { Flexible registration between different } \\
\text { data sets }\end{array}$ \\
\hline $\begin{array}{l}\text { Registration of the planned CT with a combined } \\
\text { PET-CT }\end{array}$ & $\begin{array}{l}\text { Propagation of a structure to any registered } \\
\text { data set }\end{array}$ & $\begin{array}{l}\text { Flexible registration variable selectable in } \\
\text { both directions }\end{array}$ \\
\hline $\begin{array}{l}\text { Automatic registration error measured in a } \\
\text { phantom } \leq 1 \mathrm{~mm}\end{array}$ & $\begin{array}{l}\text { The propagated structure automatically } \\
\text { receives a new name and / or a specific index }\end{array}$ & $\begin{array}{l}\text { Automatic registration error measured in } \\
\text { a phantom } \leq 0.2 \mathrm{~mm}\end{array}$ \\
\hline $\begin{array}{l}\text { Structures can be copied to both sides between } \\
\text { rigid registered data sets }\end{array}$ & $\begin{array}{l}\text { Correction tools for example to cleanup pixels } \\
\text { out of a selected VOI }\end{array}$ & $\begin{array}{l}\text { Structures can be copied to both sides } \\
\text { between flexible registered data sets }\end{array}$ \\
\hline
\end{tabular}

Structure from one dataset is representable in all registered data sets

Boolian operations (AND, OR, NOT)

Automatic expansion and contraction of structures with margins selectable in all three-dimensional directions

Density override

\begin{tabular}{|c|c|c|}
\hline \multicolumn{3}{|c|}{ Requirements for treatment planning } \\
\hline Minimal & Enhanced & Optimal \\
\hline $\begin{array}{l}\text { Conventional IMRT possible (step-and-shoot or } \\
\text { sliding-window IMRT) }\end{array}$ & Volumetric IMRT possible (e.g. RapidArc or VMAT) & $\begin{array}{l}\text { Volumetric IMRT with more than one arc } \\
\text { and selectable segments }\end{array}$ \\
\hline $\begin{array}{l}\text { Create sum of treatment plans calculated on } \\
\text { one data set }\end{array}$ & $\begin{array}{l}\text { Direct manual manipulation of the fluences } \\
\text { possible }\end{array}$ & Biological optimization and calculation \\
\hline $\begin{array}{l}\text { Use of more than one isocenter in one treatment } \\
\text { plan }\end{array}$ & $\begin{array}{l}\text { IMRT optimization with a DVH based declaration } \\
\text { of the constrains }\end{array}$ & Flattening filter free mode planning \\
\hline Non-coplanar fields are applicable (even for IMRT) & $\begin{array}{l}\text { Dose and field entries and exits presentable } \\
\text { on the body contour }\end{array}$ & $\begin{array}{l}\text { Create sum of treatment plans calculated } \\
\text { on flexible registered data sets }\end{array}$ \\
\hline $\begin{array}{l}\text { Display option of a structure in the BEV (e.g. for } \\
\text { adjustment of saturation fields) }\end{array}$ & $\begin{array}{l}\text { Reference dose can be applied to the treatment } \\
\text { plan without linking to an anatomic location of } \\
\text { the data set }\end{array}$ & $\begin{array}{l}\text { Fit of isodoses to PTV or OAR by dragging } \\
\text { the isodoses }\end{array}$ \\
\hline $\begin{array}{l}\text { Possibility of using a treatment plan as a base } \\
\text { dose plan for a new optimization }\end{array}$ & TCP and NTCP model calculation included & \\
\hline \multicolumn{3}{|l|}{ Convert an isodose to a structure } \\
\hline \multicolumn{3}{|l|}{$\begin{array}{l}\text { Calculation and export of dose matrices (fluence) } \\
\text { in transversal, sagittal and coronar slices }\end{array}$} \\
\hline \multicolumn{3}{|l|}{$\begin{array}{l}\text { Transfer of the fluence distribution on any } C T \\
\text { data set and any phantom for the physical } \\
\text { verification of dose }\end{array}$} \\
\hline Adjustable calculation grid & & \\
\hline
\end{tabular}

Adjustable calculation grid

2D fluoroscopic images and CBCT images producible in the treatment room directly before any fraction

Fast execution, high solution, good clinical image quality

Image overlay between the DRR of the treatment plan and the verification images (2D planar images)

Image overlay between the CT slices of the treatment plan and the verification images (CBCT)

Automatic matching and manual matching possible 
Table 3 Requirements for efficiency

\begin{tabular}{|c|c|c|}
\hline \multicolumn{3}{|c|}{ Data import, data registration and structure contouring } \\
\hline Minimal & Enhanced & Optimal \\
\hline \multirow[t]{5}{*}{ 2D brush, 2D pencil, 2D rubber } & $\begin{array}{l}\text { Possibility of choosing the CT slices, which } \\
\text { should be imported (some treatment } \\
\text { planning system are not able to handle } \\
\text { too much slices), manually }\end{array}$ & $\begin{array}{l}\text { Possibility of choosing the } \mathrm{CT} \text { slices, which } \\
\text { should be imported (faster treatment } \\
\text { planning), manually }\end{array}$ \\
\hline & Automatic contouring of the body contour & $\begin{array}{l}\text { All structures are created automatically } \\
\text { after selection of the treatment scheme }\end{array}$ \\
\hline & \multirow[t]{3}{*}{ Undo function } & $\begin{array}{l}\text { Propagated structures are automatically } \\
\text { adapted to the new data set }\end{array}$ \\
\hline & & $\begin{array}{l}\text { 3D brush, deformable brush, structures } \\
\text { stretchable, 3D rubber, structures can be } \\
\text { drawn in sagittal and coronal slices }\end{array}$ \\
\hline & & Automatic segmentation of all organs at risk \\
\hline & \multicolumn{2}{|l|}{ Requirements for treatment planning } \\
\hline Minimal & Enhanced & Optimal \\
\hline IMRT optimization with a pencil beam algorithm & $\begin{array}{l}\text { Optimization time for a common } \\
\text { conventional IMRT <15 min. }\end{array}$ & $\begin{array}{l}\text { Optimization time for a common } \\
\text { conventional IMRT }<5 \text { min. }\end{array}$ \\
\hline $\begin{array}{l}\text { Automatic positioning of the leafs in a defined } \\
\text { distance to the PTV }\end{array}$ & $\begin{array}{l}\text { User defined DVH with an automatic display } \\
\text { of OAR and PTV limits (green all well, yellow } \\
\text { clinically acceptable, red out of limit, } \\
\text { implementation of actual literature included } \\
\text { and changes possible) }\end{array}$ & $\begin{array}{l}\text { User defined print option using one button } \\
\text { with possible inclusion of e.g. individual } \\
\text { tables (Adaption of national laws) }\end{array}$ \\
\hline \multirow[t]{2}{*}{$\begin{array}{l}\text { Optimization time for a common Conventional } \\
\text { IMRT <30 min. }\end{array}$} & & $\begin{array}{l}\text { Simple creation of QA plans or Service } \\
\text { used plans (goal with one button) }\end{array}$ \\
\hline & & $\begin{array}{l}\text { Clinical protocols for all tumor entities with } \\
\text { automatically linked dose concepts, structure } \\
\text { templates, OAR structure templates, OAR } \\
\text { dose constraint templates, treatment plan } \\
\text { and optimization templates }\end{array}$ \\
\hline
\end{tabular}

\section{Requirements for the ROKIS}

\begin{tabular}{lll}
\hline Minimal & Enhanced & Optimal \\
\hline License always available on every ROKIS & Integrated software concept with treatment & QA Mode capability: Treatment of all \\
workstation & $\begin{array}{l}\text { planning, treatment delivery, patient } \\
\text { verification among others (except } C T \text { ) in } \\
\text { the ROKIS }\end{array}$ & $\begin{array}{l}\text { treatment plans for QA purposes possible } \\
\text { with corresponding rights }\end{array}$
\end{tabular}

Specific and clearly understandable error Fast system messages

Anonymization of patient data included (e.g. for data export and clinical studies)

Possibility to open one or more sessions per workstation

\section{Requirements for patient verification}

\begin{tabular}{lcc}
\hline Minimal & Enhanced & Optimal \\
\hline $\begin{array}{l}\text { Verification data correctable at any time } \\
\text { after treatment (offline analysis possible) }\end{array}$ & \\
\hline
\end{tabular}

should only be laid on the calculation algorithm only [7], which should either be a collapsed cone, Monte Carlo or an equivalent algorithm for best accuracy (Table 2). To create a sum out of any treatment plans (independent of the data sets) is the absolute basic tool and should be particularly emphasized. This tool should be queried before any decisions concerning the software are made, because, for example, a manual estimation of the total lung dose from two different treatment plans can result in large discrepancies between estimated and real applied dose. The software can solve these discrepancies. The possibility of using a treatment plan for a new optimization or to convert an isodose into a structure is a very useful tool for the assessment of the preload. This is important for the dose accuracy of retreated patients which becomes more and more important not only in the high precision therapy, but also in the normal clinical routine. 
Table 4 Requirements adaptive treatment

\begin{tabular}{lll}
\hline & Requirements for accuracy & \\
\hline Minimal & Enhanced & Optimal \\
\hline $\begin{array}{l}\text { Automatic link of the CBCT images to the corresponding } \\
\text { treatment plan and } C T \text { (the applied shift on treatment } \\
\text { table must be integrated in the link) }\end{array}$ & $\begin{array}{l}\text { Adaptive system automatically indicates if } \\
\text { a new treatment plan is clinically needed } \\
\text { (predefined limits by the user) }\end{array}$ & $\begin{array}{l}\text { Adaptive system automatically creates a } \\
\text { new treatment plan if clinically needed } \\
\text { (predefined limits by the user) }\end{array}$ \\
\hline Minimal & Requirements for efficiency & \\
\hline
\end{tabular}

Automatic transfer from the CBCT images to the

treatment system

For online adaptive treatment: automatic propagation

and adaption of the original structures and the original

plan including sum plan and DVH of the sum

Currently more and more treatment plans with more than one target volume and only one isocenter or plans with an integrated boost are generated [8]. For these modalities new software features are needed. For treatment plans with an integrated boost, the possibility of connecting two different single and total doses to one treatment plan which both should be automatically added during the treatment series, is needed. For treatment plans with two anatomical separated target volumes (e.g. two parts of the spinal cord) it would be helpful to allow dose counting in both volumes separately. These features are important for patient safety (Table 1). But adding treatment plans can be dangerous if for example the fractionation is different and should be carefully analysed by the user. Further a possibility of presenting the field entries and exits on the body contour to check whether there is an overlap between the fields on the skin or not would be pleasant. This tool is also helpful for the analysis of the preload.
The ROKIS systems should be able to import treatment plans to archive them and to export them later on. But it is important to check if the exported treatment plan can be used again in the treatment planning system e.g. for sum plans with new treatment plans after export and reimport. Otherwise the archive can only be used for documentation. The best way is to have an integrated system of ROKIS, the treatment system and the data archive, which does not need to import and export any treatment plans. Such an integrated system is good for safety, accuracy as well as for efficiency. It also has the additional advantage that retrospective analysis of patient statistics, quality assurance and research can be done easily and comprehensively for the whole period of the system.

To have access to clinical templates with e.g. automatically linked dose concepts, structure templates, OAR structure templates, OAR dose constraint templates, treatment plan and optimization templates is very helpful for

Table 5 Requirements for respiratory gating

\begin{tabular}{|c|c|c|}
\hline \multicolumn{3}{|c|}{ Requirements for accuracy } \\
\hline Minimal & Enhanced & Optimal \\
\hline Planning system supports 4D-CT data sets & $\begin{array}{l}\text { IMRT technique used can be applied } \\
\text { in gated mode }\end{array}$ & $\begin{array}{l}\text { Automatic propagation of the structures between } \\
\text { the different phases }\end{array}$ \\
\hline Planning system supports the localizer used & $\begin{array}{l}\text { Patient verification can be done with } \\
\text { respiratory gating }(C B C T)\end{array}$ & Patient verification can be done with $4 \mathrm{D}-\mathrm{CBCT}$ \\
\hline $\begin{array}{l}\text { Planning system supports amplitude gating and } \\
\text { phase gating }\end{array}$ & & $\begin{array}{l}\text { Registration of } 4 \mathrm{D} \text { planning-CT with } 4 \mathrm{D}-\mathrm{CBCT} \text { is } \\
\text { possible }\end{array}$ \\
\hline \multicolumn{3}{|l|}{$\begin{array}{l}\text { Register of diagnostic data sets to the } 4 D \text { data } \\
\text { set is possible }\end{array}$} \\
\hline \multicolumn{3}{|l|}{$\begin{array}{l}\text { Planning system can create an ITV out of GTV's } \\
\text { contoured in different phases }\end{array}$} \\
\hline \multicolumn{3}{|l|}{ Structure copy from one to another phase is possible } \\
\hline \multicolumn{3}{|l|}{$\begin{array}{l}\text { Patient verification can be done with respiratory } \\
\text { gating ( } 2 \mathrm{D} \text { planar radiographics) }\end{array}$} \\
\hline $\begin{array}{l}\text { Data transfer of the chosen gating window possible } \\
\text { between } C T \text {, planning system and treatment system }\end{array}$ & & \\
\hline
\end{tabular}


the clinical routine to improve the efficiency. Also treatment concept standardization can be integrated in the software to increase uniformity of treatment schedules.

It is essential that the treatment plan can automatically (!) be linked to the corresponding patient to avoid mistakes (Table 1). Even more important is the automatic link of the verification images to the patient, both the verification images of the treatment plans and the verification images from the treatment system. A link of the verification image to the corresponding field of the treatment plan would be even better. A permanent link between the patient, the clinical prescription, the treatment plan and the verification images is the most desired solution for optimal safety.

For patient verification nearly all functionalities must be declared as "minimal requirements". General patient verification is essential for high precision therapy [9]. It must be accurate, fast and as far as possible automatically efficient. Because of the high radiation exposure and the large time requirements for $\mathrm{CBCT}$ [10], the 2D planar imaging modality in the treatment room is also desirable [11]. The image modality must include direct image overlay for both modalities, because the error ratio of a layer overlay is too large. Whether automatic matching is more precise than manual matching is not demonstrated, but it is evidently faster. The demand of an automatic calculation of a 3D correction vector and automatic correction of the treatment table by the system is fundamental for the safety in high precision therapy.

For adaptive planning all "minimal requirements" for high precision therapy must be fulfilled (Table 4). Additional features such as automatic transfer from CBCT images to the treatment system with an automatic link of the $\mathrm{CBCT}$ images to the corresponding treatment plan and CT should be possible. Also important for offline adaption (Table 5) is the fact that registration between the $\mathrm{CBCT}$ and the planning $\mathrm{CT}$ automatically equates the actually applied shift. A prerequisite for this technique is the automatic propagation of the original structures and the original plan [12], including the calculation of an actual sum plan with DVH, which can also be helpful for offline adaptive planning [13]. Online adaption is still a vision for the future but not unachievable [14].

For all systems the inclusion of periodical upgrades is essential. The development of the software and the software options move rapidly and the upgraded systems are mostly faster and safer. But the most important point is the fact that software systems, which were not updated, may be not compatible to newly purchased software or hardware tools.

The tables should help the user to check the necessary and additional features, which should be integrated in modern treatment planning and ROKIS sytems. We recommend a point-based system with 10 points for all maintained minimal requirements, 5 points for all maintained enhanced requirements and 1 point for all maintained optimal requirements to receive a rating number for the software system.

\section{Conclusions}

We analysed the features of different software systems, which are needed for a smooth clinical process in high precision radiotherapy treatment for a future customer. In particular the patient verification subsystem needs a detailed examination. All minimal requirements should be fulfilled. Other requirements will make the clinical processes faster or more precise.

\section{Competing interests}

The authors declare that they have no competing interests.

\section{Authors' contribution}

$\mathrm{HV}, \mathrm{KZ}$ and DMW carried out the technical analysis of the different treatment techniques. RE participated in draft of the manuscript. All authors read and approved the final manuscript.

\section{Author details}

${ }^{1}$ Radiotherapy and Radiation Oncology, University Hospital Marburg, Baldingerstrasse, Marburg 35043, Germany. ${ }^{2}$ Technische Hochschule Mittelhessen, Wiesenstraße 14, Giessen 35390, Germany. ${ }^{3}$ Radiotherapy and Radiation Oncology, University Hospital Göttingen, Robert-Koch-Strasse 40, Göttingen 37099, Germany.

Received: 1 July 2013 Accepted: 11 June 2014

Published: 23 June 2014

\section{References}

1. Ruan D, Shao W, Demarco J, Tenn S, King C, Low D, Kupelian P, Steinberg M: Evolving treatment plan quality criteria from institution-specific experience. Med Phys 2012, 39:2708-2712.

2. Liu F, Hu Y, Zhang Q, Kincaid R, Goodman KA, Mageras GS: Evaluation of deformable image registration and a motion model in $\mathrm{CT}$ images with limited features. Phys Med Biol 2012, 57:2539-2554.

3. Hou J, Guerrero M, Chen W, D'Souza WD: Deformable planning CT to cone-beam CT image registration in head-and-neck cancer. Med Phys 2011, 38:2088-2094.

4. Deeley MA, Chen A, Datteri R, Noble JH, Noble JH, Cmelak AJ, Donnelly EF, Malcolm AW, Moretti L, Jaboin J, Niermann K, Yang ES, Yu DS, Yei F, Koyama T, Ding GX, Dawant BM: Comparison of manual and automatic segmentation methods for brain structures in the presence of space-occupying lesions: a multi-expert study. Phys Med Biol 2011, 56:4557-4577

5. Hibbard LS: Anatomy structure creation and editing using 3D implicit surfaces. Med Phys 2012, 39:2649-2658.

6. Petric MP, Clark BG, Robar JL: A comparison of two commercial treatment-planning systems to IMRT. J App/ Clin Med Phys 2005, 6:63-80.

7. Nielsen TB, Wieslander E, Fogliata A, Nielsen M, Hansen O, Brink C: Influence of dose calculation algorithms on the predicted dose distribution and NTCP values for NSCLC patients. Med Phys 2011, 38:2412-2418.

8. Hurkmans CW, Dijckmans I, Reijnen M, van der Leer J, van VlietVroegindeweij C, van der Sangen M: Adaptive radiation therapy for breast IMRT-simultaneously integrated boost: Three-year clinical experience. Radiother Oncol 2012, 103:183-187.

9. Li R, Mok E, Han B, Koong A, Xing L: Evaluation of the geometric accuracy of surrogate-based gated VMAT using intrafraction kilovoltage x-ray images. Med Phys 2012, 39:2686-2693.

10. Abou-Elenein HS, Attalla EM, Ammar H, Eldesoky I, Farouk M, Zaghloul MS: Megavoltage cone beam computed tomography: Commissioning and evaluation of patient dose. J Med Phys 2011, 36:205-212. 
11. Ali I, Tubbs J, Hibbitts K, Algan O, Thompson S, Herman T, Ahmad S: Evaluation of the setup accuracy of a stereotactic radiotherapy head immobilization mask system using kV on-board imaging. J App/ Clin Med Phys 2010, 11:3192.

12. Olteanu LA, Madani I, De Neve W, Vercauteren T, De Gersem W: Evaluation of deformable image coregistration in adaptive dose painting by numbers for head-and-neck cancer. Int J Radiat Oncol Biol Phys 2012, 83:696-703.

13. Prabhakar R, Rath GK: A simple plan evaluation index based on the dose to critical structures in radiotherapy. J Med Phys 2011, 36:192-197.

14. Korreman S, Rasch C, McNair H, Verellen D, Oelfke U, Maingon P, Mijnheer B, Khoo V: The European Society of Therapeutic Radiology and OncologyEuropean Institute of Radiotherapy (ESTRO-EIR) report on 3D CT-based in-room image guidance systems: a practical and technical review and guide. Radiother Oncol 2010, 94:129-144.

doi:10.1186/1748-717X-9-145

Cite this article as: Vorwerk et al:: Making the right software choice for clinically used equipment in radiation oncology. Radiation Oncology 2014 9:145.

\section{Submit your next manuscript to BioMed Central and take full advantage of:}

- Convenient online submission

- Thorough peer review

- No space constraints or color figure charges

- Immediate publication on acceptance

- Inclusion in PubMed, CAS, Scopus and Google Scholar

- Research which is freely available for redistribution 